\title{
Progesterone receptor gene polymorphisms and risk of endometriosis: results from an international collaborative effort
}

\section{Citation}

Near, Aimee M., Anna H. Wu, Claire Templeman, David J. Van Den Berg, Jennifer A. Doherty, Mary Anne Rossing, Ellen L. Goode, et al. 2011. "Progesterone Receptor Gene Polymorphisms and Risk of Endometriosis: Results from an International Collaborative Effort." Fertility and Sterility 95 (1) (January): 40-45. doi:10.1016/j.fertnstert.2010.06.059.

\section{Published Version}

doi:10.1016/j.fertnstert.2010.06.059

\section{Permanent link}

http://nrs.harvard.edu/urn-3:HUL.InstRepos:27336916

\section{Terms of Use}

This article was downloaded from Harvard University's DASH repository, and is made available under the terms and conditions applicable to Other Posted Material, as set forth at http:// nrs.harvard.edu/urn-3:HUL.InstRepos:dash.current.terms-of-use\#LAA

\section{Share Your Story}

The Harvard community has made this article openly available.

Please share how this access benefits you. Submit a story.

Accessibility 


\title{
Progesterone Receptor Gene Polymorphisms and Risk of Endometriosis: Results from an International Collaborative Effort
}

\begin{abstract}
Aimee M. Near, M.P.H ${ }^{1}$, Anna H. Wu, Ph.D. ${ }^{2}$, Claire Templeman, M.D. ${ }^{3}$, David J. Van Den Berg, Ph.D. ${ }^{2}$, Jennifer A. Doherty, Ph.D. ${ }^{4}$, Mary Anne Rossing, Ph.D. ${ }^{4}$, Ellen L. Goode, Ph.D. ${ }^{5}$, Julie M. Cunningham, Ph.D. ${ }^{5}$, Robert A. Vierkant, Ph.D. ${ }^{5}$, Brooke L. Fridley, Ph.D. ${ }^{5}$, Georgia Chenevix-Trench, Ph.D. ${ }^{6}$, Penelope M. Webb, Ph.D. ${ }^{6}$, The Australian Cancer Study (Ovarian Cancer) (ACS) ${ }^{6}$, The Australian Ovarian Cancer Study Group (AOCS) ${ }^{7}$, Susanne Krüger Kjær, M.D. ${ }^{8}$, Estrid Hogdall, M.D. ${ }^{8}$, Simon A. Gayther, Ph.D. ${ }^{9}$, Susan J. Ramus, Ph.D. ${ }^{9}$, Usha Menon, M.D. ${ }^{9}$, Aleksandra Gentry-Maharaj, Ph.D. ${ }^{9}$, Joellen M. Schildkraut, Ph.D. ${ }^{10}$, Patricia G. Moorman, Ph.D. ${ }^{11}$, Rachel T. Palmieri, M.S.P.H ${ }^{12}$, Roberta B. Ness, M.D. ${ }^{13}$, Kirsten Moysich, Ph.D. ${ }^{14}$, Daniel W. Cramer, M.D. ${ }^{15}$, Kathryn L. Terry, Ph.D. ${ }^{15}$, Allison F. Vitonis, Ph.D. ${ }^{15}$, Malcolm C. Pike, Ph.D. ${ }^{2}$, Andrew Berchuck, M.D. ${ }^{11}$, and Celeste Leigh Pearce, Ph.D. ${ }^{2}$ on behalf of the Ovarian Cancer Association Consortium ${ }^{1}$ Cancer Control Program, Lombardi Comprehensive Cancer Center, Georgetown University Medical Center, Washington, D.C, USA

${ }^{2}$ Department of Preventive Medicine, Keck School of Medicine, University of Southern California, Los Angeles, CA, USA

${ }^{3}$ Department of Gynecology, Keck School of Medicine, University of Southern California, Los Angeles, CA, USA

${ }^{4}$ Program in Epidemiology, Fred Hutchinson Cancer Research Center, Seattle, WA, USA

${ }^{5}$ Department of Health Sciences Research, Mayo Clinic College of Medicine, Rochester, MN, USA

${ }^{6}$ The Queensland Institute of Medical Research, Brisbane, Australia

${ }^{7}$ Peter MacCallum Cancer Centre, East Melbourne, Australia

${ }^{8}$ Department of Virus, Hormones and Cancer Institute of Cancer Epidemiology, Danish Cancer Society, Copenhagen, Denmark

${ }^{9}$ Department of Gynaecological Oncology, University College London, EGA Institute for Women's Health, London, UK

${ }^{10}$ Department of Community and Family Medicine, Duke University Medical Center, Durham, NC, USA

${ }^{11}$ Department of Obstetrics and Gynecology, Duke University Medical Center, Durham, NC, USA
\end{abstract}

\footnotetext{
(C) 2010 Published by Elsevier Inc on behalf of American Society for Reproductive Medicine.

Cooresponding Author: C. Leigh Pearce, 1441 Eastlake Avenue NTT4415 MC-9175, Los Angeles, CA 90089. (323) 865-0437 cpearce@usc.edu.

Publisher's Disclaimer: This is a PDF file of an unedited manuscript that has been accepted for publication. As a service to our customers we are providing this early version of the manuscript. The manuscript will undergo copyediting, typesetting, and review of the resulting proof before it is published in its final citable form. Please note that during the production process errors may be discovered which could affect the content, and all legal disclaimers that apply to the journal pertain.
} 
${ }^{12}$ Department of Epidemiology, Gillings School of Global Public Health, University of North Carolina at Chapel Hill, Chapel Hill, NC, USA

${ }^{13}$ University of Texas, School of Public Health, Houston, TX, USA

${ }^{14}$ Department of Cancer Genetics, Roswell Park Cancer Institute, Buffalo, NY, USA

${ }^{15}$ Obstetrics and Gynecology Epidemiology Center, Brigham and Women's Hospital, Boston, MA, USA

\section{Abstract}

Objective-To investigate the association between self-reported endometriosis and the putative functional promoter $+331 \mathrm{C} / \mathrm{T}$ single nucleotide polymorphism (SNP) and the PROGINS allele.

Design-Control subjects from ovarian cancer case-control studies participating in the international Ovarian Cancer Association Consortium. The majority of controls are drawn from population-based studies.

Setting-An international ovarian cancer consortium including studies from the Australia, Europe and the United States,

Patients-5,812 White female controls, of whom 348 had endometriosis, from eight ovarian cancer case-control studies.

Interventions-None.

Main Outcome Measures-Genotypes for the $+331 \mathrm{C} / \mathrm{T}$ SNP and PROGINS allele and a history of endometriosis.

Results-The occurrence of endometriosis was reduced in women carrying one or more copies of the $+331 \mathrm{~T}$ allele $(\mathrm{OR}=0.65$; 95\% CI: $0.43-0.98, \mathrm{p}=0.042)$, whereas there was no association between the PROGINS allele and endometriosis $(\mathrm{OR}=0.94,95 \%$ CI $0.76,1.16)$.

Conclusions-Additional studies of the $+331 \mathrm{C} / \mathrm{T}$ variant are warranted given the current finding and the equivocal results of previous studies. The $+331 \mathrm{~T}$ allele has been shown to result in a reduced PR-A to PR-B ratio and if the observed association with endometriosis is confirmed it would suggest that this ratio is important for this disease.

\section{Keywords}

Endometriosis; progesterone receptor; ovarian cancer; PROGINS

\section{Introduction}

Endometriosis affects approximately 5-10\% of reproductive-age women (1) and this figure may be substantially higher in women presenting with pelvic pain and/or infertility where surgical intervention is often required. In addition, women with a history of endometriosis also have an increased risk of endometrioid and clear cell ovarian cancer (2-5).

Similar to ovarian cancer, endometriosis is stimulated by estrogens and inhibited by progesterone (6). The actions of progesterone are mediated by the progesterone receptor, which is encoded by the $P G R$ gene on chromosome 11q22-q23 (7). Through two promoter and translational start sites, the $P G R$ gene encodes the PR-A and PR-B isoforms of the receptor. Although structurally similar, the actions of PR-A and PR-B differ: PR-B is a transcriptional activator of progesterone target genes, whereas PR-A acts as a repressor of PR-B (8). 
A putative functional polymorphism in the promoter region of the PGR, $+331 \mathrm{C} / \mathrm{T}$ (rs10895068), creates an additional TATA box, which provides a unique transcriptional start site that favors increased production of PR-B relative to PR-A (9). Due to increased production of PR-B, this variant has been suggested to reduce the risk of endometriosis as has been shown with endometrioid and clear cell ovarian cancer (10). Attia et al. (11) reported lower levels of PR-A in endometriotic tissue compared to paired samples of eutopic endometrium. PR-B was expressed in 17 of 18 eutopic samples, but there was no PR-B expression in endometriotic tissue (11).

Berchuck et al. first suggested a reduced risk of endometriosis with the $\mathrm{T}$ allele of the +331 variant in a study of control women who were participants in a case-control study of ovarian cancer in North Carolina (12). This reduced risk was also found in one study of deep infiltrating endometriosis (13), but an increased risk was found in a second study (14). Treloar and colleagues found no association with endometriosis and this variant (15).

Another putative functional variant in the PGR, PROGINS, has also shown equivocal results with respect to an association with endometriosis. Several studies have suggested that the variant increases susceptibility to endometriosis (16-18) while others have found no association $(13,15,19)$. A large pooled analysis of ovarian cancer risk and PROGINS showed no overall association, but an increased risk associated with the endometrioid subtype (10).

We present here the results of our analysis of the association between self-reported endometriosis and the $+331 \mathrm{C} / \mathrm{T}$ and PROGINS variants in a pooled analysis of eight different control populations from the U.S., Australia and Europe that are part of the Ovarian Cancer Association Consortium (OCAC).

\section{Materials and Methods}

\section{Study Populations}

Seven population-based and one clinic-based (MAYO) ovarian cancer case-control studies contributed to this analysis. The groups contributing data include the Australian Cancer Study and the Australian Ovarian Cancer Study (AUS), the western Washington State Ovarian Cancer Case-Control Study (DOVE), the Hormones and Ovarian Cancer Prediction Study of Delaware Valley (HOPE), the Danish Malignant Ovarian Cancer Study (MALOVA), the Mayo Clinic Ovarian Cancer Case-Control Study (MAYO), the North Carolina Ovarian Cancer Study (NCOCS), the New England-based Case-Control Study (NECC), and the Los Angeles County Case-Control Studies of Ovarian Cancer (USC). The original report on +331 and endometriosis from Berchuck and colleagues (12) included a smaller subset of subjects from the NCOCS than those used in the current study. The results presented here are limited to the White control subjects from these studies.

Details of these studies, including methods of control ascertainment, data collection and participation rates, are provided in Table 1 and have been described previously $(10,20,21)$. Data collection included information regarding menstrual, reproductive, and gynecologic histories; birth control and hormone use; and lifestyle factors. Endometriosis was selfreported. In addition, blood or saliva samples were collected for DNA extraction. These are the same studies we previously evaluated for association with ovarian cancer risk described in a study by Pearce et al. (10), but with the CONN, FROC, POCS and SEARCH studies excluded from the current analysis because they did not have data on endometriosis. 


\section{Genotyping and Quality Control}

The two PGR SNPs genotyped for this analysis were +331C/T (rs 10895068) and PROGINS (rs1042838). The PROGINS allele was measured by the exon 4 missense SNP (rs1042838) which is in perfect linkage disequilibrium with the ALU insertion first used to define the PROGINS allele. Allele designations were based on the forward strand as given in the University of California at Santa Cruz (UCSC) genome browser (10). DOVE, HOPE, MALOVA, NCOCS, NECC and USC used the 5' nuclease Taqman allelic discrimination assay (Applied Biosystems, Foster City, CA) for genotyping. ACS and AOCS used the iPlex Sequenom MassArray system (Sequenom Inc., San Diego, CA) and MAYO used Pyrosequencing for genotyping. Laboratory to laboratory quality control was assessed by genotyping a common set of 90 DNAs that showed greater than $99 \%$ concordance. Concordance between duplicate samples in each individual study was $>98 \%$ for both SNPs. Hardy-Weinberg equilibrium (HWE) for the two polymorphisms was confirmed among White controls for each study using the $\chi^{2}$ goodness-of-fit test (Table 1).

\section{Statistical Analysis}

Endometriosis was a dichotomous outcome (yes/no). MALOVA data were included even though the prevalence of endometriosis in controls was very low (1.0\%) because the investigators found that after reviewing their data collection procedures they had no reason to doubt this variable would not accurately reflect the reports of the study subjects. The results of analyses conducted with and without the MALOVA study were similar. Endometriosis rates for the other seven studies were in line with expectations.

Unconditional logistic regression was used to evaluate the association between endometriosis (outcome) and genotype. All analyses were stratified on study and age ( $<40$, 40-49, 50-59, 60-69, 70+). A log additive genetic model was used for the PROGINS variant as there was no a priori reason to believe this variant acts under a different model. Odds ratios (ORs) and 95\% confidence intervals (CIs) are expressed per copy of the minor allele carried for PROGINS. For $+331 \mathrm{C} / \mathrm{T}$, the minor allele frequency was only $6 \%$, therefore this SNP was modeled using a dichotomous variable and all ORs and 95\% CIs for this variant depict associations for heterozygotes and rare homozygotes combined compared to common homozygotes (i.e., dominant genetic model). All statistical significance levels (p-values) quoted are two-sided. Heterogeneity by study site was evaluated by the likelihood ratio (LR) test comparing models with and without cross-product terms representing study site and genotype. Analyses were conducted using SAS (Version 9.1, SAS Institute, Cary, NC).

\section{Approval and Consent}

All participants provided written informed consent prior to the interview and collection of biological samples. The University of Southern California and Duke University obtained institutional review board (IRB) approval to serve as data coordinating centers for the OCAC. The authors also obtained approval from the University of Michigan Institution Review Board as some analyses were conducted there as well. The investigators have no conflicts of interest to disclose.

\section{Results}

A total of 5,812 women who had served as controls for one of the ovarian cancer casecontrol studies were available for this analysis; their mean age was 55.5 years (standard deviation 11.9; range 16-91). The prevalence of endometriosis was $6.0 \%$ overall $(n=348)$; the prevalence was between 5\% and $8 \%$ in seven of the eight studies. The overall minor allele frequencies (MAFs) for $+331 \mathrm{C} / \mathrm{T}$ and PROGINS by study are shown in Table 1 . 
We found borderline evidence that endometriosis was associated with carrying one or two copies of the $+331 \mathrm{~T}$ allele $(\mathrm{OR}=0.65,95 \% \mathrm{CI}=0.43-0.98, \mathrm{p}=0.042$; Table 2$)$. This association showed no evidence of heterogeneity of effect by study $\left(p_{\text {het }}=0.53\right)$. Given the low prevalence of endometriosis in the MALOVA study, we excluded these data from the analysis and the results were unchanged (data not shown). After excluding the data from NCOCS that appeared in the initial report from Berchuck and colleagues (12), an inverse association was still observed (OR=0.72, 95\% CI $0.47,1.17)$, but the result was no longer statistically significant $(\mathrm{p}=0.13)$. The individual study ORs and $95 \% \mathrm{CIs}$ are given in Figure 1.

The association observed between endometriosis and the PROGINS allele was small and did not reach statistical significance $(\mathrm{OR}=0.94$ per copy of the minor allele, $95 \% \mathrm{CI}=0.76$ $1.16, \mathrm{p}=0.56$; Table 2 ). No evidence of heterogeneity of effect by study center was observed $\left(\mathrm{p}_{\text {het }}=0.12\right)$.

\section{Discussion}

We observed a 35\% reduction in the presence of endometriosis among carriers of the $+331 \mathrm{~T}$ allele $(95 \% \mathrm{CI} 2 \%-57 \%)$. The $+331 \mathrm{C} / \mathrm{T}$ has been shown to influence the transcription of PR-B relative to PR-A with the T allele favoring PR-B (9). PR-B acts as a classic hormone receptor, mediating the effects of progesterone whereas PR-A acts as a repressor of PR-B and as a result, the presence of the $+331 \mathrm{~T}$ allele is hypothesized to lead to a greater effect of progesterone. Our finding of a reduced risk is biologically plausible since endometriosis is responsive to progesterone.

Attia and colleagues also showed lower levels of PR-B in endometriotic lesions (11) which would be consistent with a protective role of a variant that increased PR-B and therefore progesterone responsiveness. Also, an association between the $+331 \mathrm{C} / \mathrm{T}$ variant and ovarian cancer was observed with both clear cell and endometrioid ovarian cancers, but not the other histological subtypes $(\mathrm{OR}=0.81, \mathrm{p}=0.058)(10)$.

The existing literature on the $+331 \mathrm{~T}$ allele is contradictory. After Berchuck and colleagues (12) first suggested a reduced risk of endometriosis associated with the T allele of the +331 variant, Treloar et al. (15) conducted a large study which included more than 900 families (child-parent trios) and found no association. Van Kaam and colleagues (13) reported a 33\% decreased risk for deep infiltrating endometriosis in women who carry the $+331 \mathrm{~T}$ allele (13), but this is in the opposite direction from that reported by Gentilini et al (14). However, both the studies of van Kaam et al. and Gentilini et al. were hospital-based and utilized controls with gynecological conditions and those referred for genetic testing so it is possible that the differences found were due to inadequate control selection. Also, both studies were small, with less than 100 and 200 cases, respectively. Furthermore, the CT and TT combined genotype frequencies reported for the general White control populations (those referred for genetic testing) by van Kaam et al. (18.3\%) (13) and Gentilini et al. (4.3\%) (14) are high and low, respectively, compared to that found in the eight White populations included in our study (8\%-14\%), including the European MALOVA study (14\%). This difference in genotype frequencies may account for the difference in findings between these two studies. Also, genotyping quality control measures are not adequately described for either the van Kaam et al. or Gentilini et al. studies $(13,14)$. All of these design issues make the results of these two studies difficult to interpret. However, the null study from Treloar and colleagues for which all women with endometriosis were surgically confirmed does not suffer from such design issues (15), leaving open the possibility that our finding is due to chance, particularly given the borderline statistically significant $\mathrm{p}$-value that we observed $(\mathrm{p}=0.042)$. 
Further research is warranted to clarify the role of the +331 variant in the development of endometriosis.

There was no association between the PROGINS allele and risk of endometriosis ( $\mathrm{p}=0.56$ ). While these findings fail to support three previous studies which suggested an increase in susceptibility to endometriosis in women carrying the PROGINS allele (16-18), they are in accordance with the results found by Treloar et al. (15), van Kaam et al. (13) and Govindan et al. (19). The observation of no association may not be surprising given that the association between the PROGINS and ovarian cancer risk was observed with endometrioid ovarian cancer, but not the clear cell subtype.

This study was conducted among controls from a set of eight ovarian cancer case-control studies. The prevalence of endometriosis reported among control women is compatible with most population estimates of endometriosis (1) and our study is large compared with most other reports in the literature. The controls appear representative of women in the areas where these studies were conducted. Importantly, there was also no evidence of heterogeneity among the eight studies pooled for this analysis supporting the validity of the findings.

All of the endometriosis data are based on self-report of a physician diagnosis. There is undoubtedly some misclassification of endometriosis diagnosis among affected individuals given that the condition was not necessarily surgically confirmed. Similarly, it is possible that women who reported no endometriosis could have the disease, but not have been diagnosed or informed of this diagnosis by their physician. The major limitation of this study is the small number of women with endometriosis $(n=348)$ which restricts the statistical power to detect associations at very stringent levels of significance. The number of OCAC members is growing and represent a powerful forum in which to conduct genetic association studies as well as to explore in more detail the association between ovarian cancer risk and endometriosis. Extensive questionnaire data are available from many of the OCAC studies which allows for the evaluation of other factors such as oral contraceptive use. Additionally, we are able to examine the role of ovarian cancer histological subtype associated with endometriosis in this collaborative effort. Such studies are underway.

We have provided suggestive evidence for a role of variation in the PGR gene with endometriosis. The clinical implications of this finding are not clear at this point, but our results indicate that progesterone signaling may be important in this disease. Additional follow-up is warranted to further examine this relationship with endometriosis and the +331 variant as well as to explore the potential synergistic relationship between endometriosis, PGR variation and ovarian cancer risk.

\section{Acknowledgments}

Acknowledges of Financial Support:

The Ovarian Cancer Association Consortium is funded by the Ovarian Cancer Research Fund. The AOCS Management Group (D. Bowtell, G. Chenevix-Trench, A. deFazio, D. Gertig, A. Green, P. Webb) gratefully acknowledges the contribution of all the clinical and scientific collaborators (see http://www.aocstudy.org/). The ACS Management Group comprises A. Green, P. Parsons, N. Hayward, P. Webb, D. Whiteman. Financial support was provided by U.S. Army Medical Research and Materiel Command under DAMD17-01-1-0729, the Cancer Council Tasmania and Cancer Foundation of Western Australia (AOCS study), and the National Health and Medical Research Council of Australia (199600) (ACS study). GCT and PW are supported by the NHMRC.

The HOPE study was supported by grants from the Department of Defense DAMD 17-02-1-0669 and the US National Cancer Institute RO1CA095023.

The work undertaken at MAYO is supported by R01-CA122443. 
The NECC study was supported by the US National Cancer Institute grants RO1CA054419 and P50CA105009.

The work undertaken at UCLH/UCL is supported by Cancer Research UK, Medical Research Council, The Eve Appeal, Oak Foundation and the Department of Health's NIHR Biomedical Research Centres funding scheme.

The USC study was supported by the US National Cancer Institute grants P01-CA17054, CA14089, CA61132, CA63464, N01-PC67010, R03-CA113148; California Department of Health Services subcontract 050-E8709; California Cancer Research Program Grants 00-01389V-20170 and 2110200.

We are grateful to the family and friends of Kathryn Sladek Smith for their generous support of OCAC through their donations to the Ovarian Cancer Research Fund. We thank all the individuals who took part in these studies and the project staff of all the participating studies.

\section{References}

1. Vigano P, Parazzini F, Somigliana E, Vercellini P. Endometriosis: epidemiology and aetiological factors. Best Pract Res Clin Obstet Gynaecol. 2004; 18:177-200. [PubMed: 15157637]

2. Fukunaga M, Nomura K, Ishikawa E, Ushigome S. Ovarian atypical endometriosis: its close association with malignant epithelial tumours. Histopathology. 1997; 30:249-55. [PubMed: 9088954]

3. Vercellini P, Parazzini F, Bolis G, Carinelli S, Dindelli M, Vendola N, et al. Endometriosis and ovarian cancer. Am J Obstet Gynecol. 1993; 169:181-2. [PubMed: 8392791]

4. Valenzuela P, Ramos P, Redondo S, Cabrera Y, Alvarez I, Ruiz A. Endometrioid adenocarcinoma of the ovary and endometriosis. Eur J Obstet Gynecol Reprod Biol. 2007; 134:83-6. [PubMed: 16844279]

5. Sainz de la Cuesta R, Eichhorn JH, Rice LW, Fuller AF Jr, Nikrui N, Goff BA. Histologic transformation of benign endometriosis to early epithelial ovarian cancer. Gynecol Oncol. 1996; 60:238-44. [PubMed: 8631545]

6. Ness RB. Endometriosis and ovarian cancer: thoughts on shared pathophysiology. Am J Obstet Gynecol. 2003; 189:280-94. [PubMed: 12861175]

7. Rousseau-Merck MF, Misrahi M, Loosfelt H, Milgrom E, Berger R. Localization of the human progesterone receptor gene to chromosome 11q22-q23. Hum Genet. 1987; 77:280-2. [PubMed: 3679212]

8. Vegeto E, Shahbaz MM, Wen DX, Goldman ME, O’Malley BW, McDonnell DP. Human progesterone receptor A form is a cell- and promoter-specific repressor of human progesterone receptor B function. Mol Endocrinol. 1993; 7:1244-55. [PubMed: 8264658]

9. De Vivo I, Huggins GS, Hankinson SE, Lescault PJ, Boezen M, Colditz GA, et al. A functional polymorphism in the promoter of the progesterone receptor gene associated with endometrial cancer risk. Proc Natl Acad Sci U S A. 2002; 99:12263-8. [PubMed: 12218173]

10. Pearce CL, Wu AH, Gayther SA, Bale AE, Beck PA, Beesley J, et al. Progesterone receptor variation and risk of ovarian cancer is limited to the invasive endometrioid subtype: results from the ovarian cancer association consortium pooled analysis. Br J Cancer. 2008; 98:282-8. [PubMed: 18219286]

11. Attia GR, Zeitoun K, Edwards D, Johns A, Carr BR, Bulun SE. Progesterone receptor isoform A but not B is expressed in endometriosis. J Clin Endocrinol Metab. 2000; 85:2897-902. [PubMed: 10946900]

12. Berchuck A, Schildkraut JM, Wenham RM, Calingaert B, Ali S, Henriott A, et al. Progesterone receptor promoter $+331 \mathrm{~A}$ polymorphism is associated with a reduced risk of endometrioid and clear cell ovarian cancers. Cancer Epidemiol Biomarkers Prev. 2004; 13:2141-7. [PubMed: 15598772]

13. van Kaam KJ, Romano A, Schouten JP, Dunselman GA, Groothuis PG. Progesterone receptor polymorphism $+331 \mathrm{G} / \mathrm{A}$ is associated with a decreased risk of deep infiltrating endometriosis. Hum Reprod. 2007; 22:129-35. [PubMed: 16920727]

14. Gentilini D, Vigano P, Carmignani L, Spinelli M, Busacca M, Di Blasio AM. Progesterone receptor $+331 \mathrm{G} / \mathrm{A}$ polymorphism in endometriosis and deep-infiltrating endometriosis. Fertil Steril. 2008; 90:1243-5. [PubMed: 18281038] 
15. Treloar SA, Zhao ZZ, Armitage T, Duffy DL, Wicks J, O'Connor DT, et al. Association between polymorphisms in the progesterone receptor gene and endometriosis. Mol Hum Reprod. 2005; 11:641-7. [PubMed: 16126772]

16. Wieser F, Schneeberger C, Tong D, Tempfer C, Huber JC, Wenzl R. PROGINS receptor gene polymorphism is associated with endometriosis. Fertil Steril. 2002; 77:309-12. [PubMed: 11821088]

17. Lattuada D, Somigliana E, Vigano P, Candiani M, Pardi G, Di Blasio AM. Genetics of endometriosis: a role for the progesterone receptor gene polymorphism PROGINS? Clin Endocrinol (Oxf). 2004; 61:190-4. [PubMed: 15272913]

18. De Carvalho CV, Nogueira-De-Souza NC, Costa AM, Baracat EC, Girao MJ, D'Amora P, et al. Genetic polymorphisms of cytochrome P450cl7alpha (CYP17) and progesterone receptor genes (PROGINS) in the assessment of endometriosis risk. Gynecol Endocrinol. 2007; 23:29-33. [PubMed: 17484509]

19. Govindan S, Ahmad SN, Vedicherla B, Kodati V, Jahan P, Rao KP, et al. Association of progesterone receptor gene polymorphism (PROGINS) with endometriosis, uterine fibroids and breast cancer. Cancer Biomark. 2007; 3:73-8. [PubMed: 17522428]

20. Gayther SA, Song H, Ramus SJ, Kjaer SK, Whittemore AS, Quaye L, et al. Tagging single nucleotide polymorphisms in cell cycle control genes and susceptibility to invasive epithelial ovarian cancer. Cancer Res. 2007; 67:3027-35. [PubMed: 17409409]

21. Spurdle AB, Goodwin B, Hodgson E, Hopper JL, Chen X, Purdie DM, et al. The CYP3A4*1B polymorphism has no functional significance and is not associated with risk of breast or ovarian cancer. Pharmacogenetics. 2002; 12:355-66. [PubMed: 12142725] 


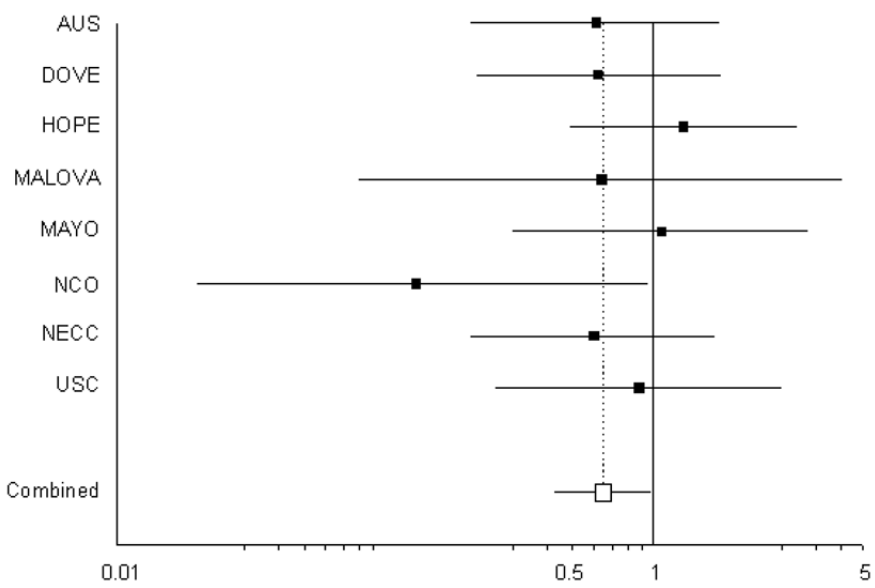

Figure 1.

Forrest plot of the association between the $+331 \mathrm{~T}$ allele and risk of endometriosis for the eight included studies. The summary odds ratio is $0.65(95 \%$ CI $0.43,0.98, \mathrm{p}=0.042)$. 


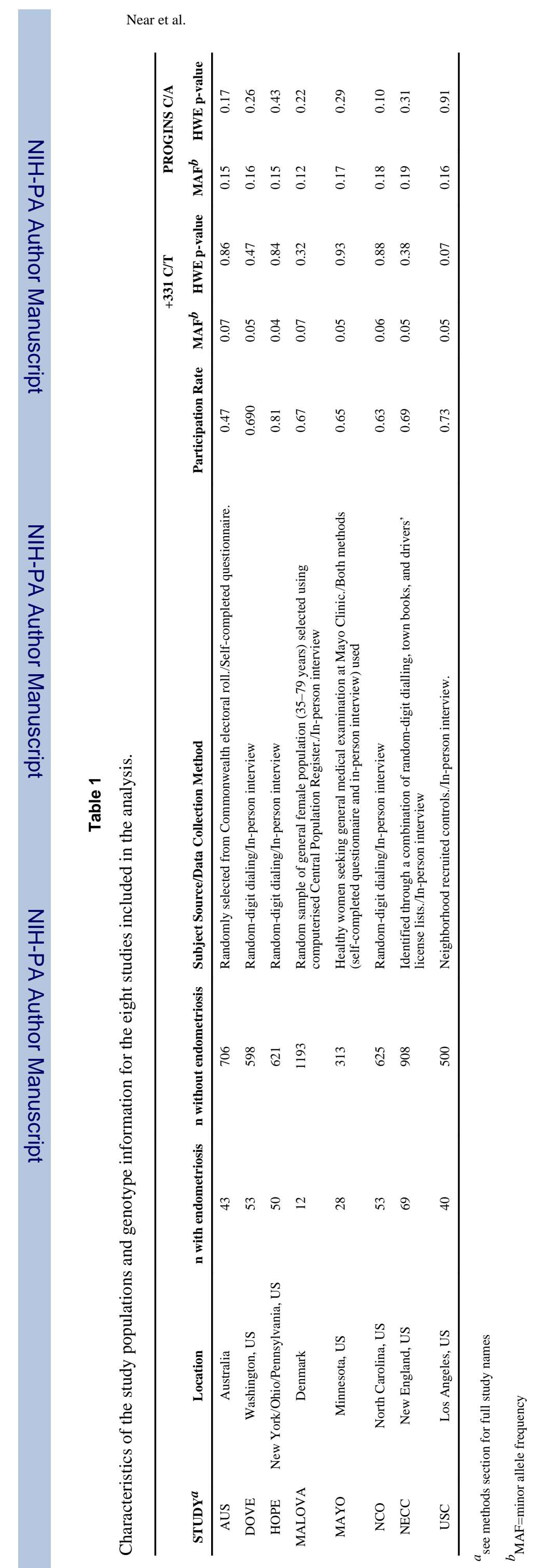

Page 10 
